Modeling, Identification and Control, Vol. 31, No. 2, 2010, pp. 55-65, ISSN 1890-1328

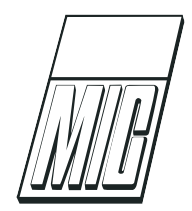

\title{
Oxygen Effects in Anaerobic Digestion - II
}

\author{
*Deshai Botheju Bernt Lie Rune Bakke
}

Faculty of Technology, Telemark University College, Kjoelnes Ring 56, 3901, P.O.Box 203, Porsgrunn, Norway; E-mail: *Deshai.Botheju@hit.no

\begin{abstract}
Standard models describing bio-gasification using anaerobic digestion do not include necessary processes to describe digester dynamics under the conditions of oxygen presence. Limited oxygenation in anaerobic digestion can sometimes be beneficial. The oxygen effects included anaerobic digestion model, ADM 1Ox, was simulated against experimental data obtained from laboratory scale anaerobic digesters operated under different oxygenation conditions. ADM 1-Ox predictions are generally in good agreement with the trends of the experimental data.

ADM 1-Ox simulations suggest the existence of an optimum oxygenation level corresponding to a peak methane yield. The positive impact of oxygenation on methane yield is more pronounced at conditions characterized by low hydrolysis rate coefficients (slowly degradable feed) and low biomass concentrations. The optimum oxygenation point moves towards zero when the hydrolysis rate coefficient and the biomass concentration increase. Accordingly, the impact of oxygenation on methane yield can either be positive or negative depending on the digestion system characteristics. The developed ADM 1-Ox model can therefore be a valuable tool for recognizing suitable operating conditions for achieving the maximum benefits from partial aeration in anaerobic digestion.
\end{abstract}

Keywords: ADM 1-Ox model, anaerobic digestion, optimum oxygenation, oxygen effects, simulation

\section{Introduction}

Anaerobic digestion (AD), as its name suggests, is a process that occurs in oxygen depleted environments. Recent research suggests, however, that a limited availability of free oxygen can be beneficial in a number of ways to make AD more efficient and flexible as a waste treatment and energy generation scheme (Johansen and Bakke, 2006; Polanco et al., 2009; Botheju et al., 2010a,b). Studying effects of limited oxygen supply in operation of AD is relevant also since maintaining meticulously anaerobic systems is often not easy.

The biochemical model, ADM 1-Ox, used to describe AD under limited aeration conditions, was presented previously (Botheju et al., 2009). ADM 1-Ox is a modified version of the widely accepted anaerobic digestion model ADM 1 (Batstone et al., 2002) developed by the International Water Association (IWA).
The aim of the present work is to further validate the ADM 1-Ox model with laboratory experimental data and also to utilize model simulations to analyze the AD process under different oxygenation levels. Experimental data from two batch phase experimental series and a (semi) continuous feed anaerobic digester, obtained under laboratory controlled conditions, are used in this regard.

\section{Methodology}

\subsection{The simulation model}

The simulations carried out here are based on the ADM 1-Ox model structure described previously (Botheju et al., 2009). ADM 1-Ox included plausible oxygen effects in anaerobic digestion by including three aerobic uptake processes for the hydrolysis products of car- 
bohydrates, proteins and lipids, modifying the hydrolysis rate equations to include the acidogenic biomass concentrations, and also including oxygen inhibition of strictly anaerobic biomass.

Some of the experimental work carried out recently (Botheju et al., 2010b) indicate that the oxidation of volatile fatty acids (VFA) due to aerobic respiration can reduce the VFA accumulation in digesters operating under partial aeration conditions. VFA are key intermediate products of $\mathrm{AD}$, formed when the substrate is being converted to methane and $\mathrm{CO}_{2}$. Hence, it is decided to further extend the ADM 1-Ox model by introducing four new aerobic substrate consumption processes to represent the aerobic respiration using four major VFA found in AD, namely acetic, propionic, butyric and valeric acids.

Since each of those four VFA can be taken up by any of the three acidogenic biomass groups, $X_{s u}, X_{a a}, X_{f a}$ (Botheju et al., 2009), no new organisms are needed in the model. The aerobic uptake rates of VFA are therefore modeled as three different parts representing the contribution of each acidogenic group. Equation (1) displays the general rate equation used for describing the aerobic uptake of acetate, propionate, butyrate and valerate.

$$
\begin{array}{r}
r_{v f a}=\left(K_{m, s u} X_{s u} I_{1}+K_{m, a a} X_{a a} I_{1}+K_{m, f a} X_{f a} I_{2}\right) \\
\cdot\left(\frac{S_{v f a}}{K_{s, v f a, a e r}+S_{v f a}}\right)\left(\frac{S_{o 2}}{K_{o 2}+S_{o 2}}\right)
\end{array}
$$

The affinity constants $K_{s, v f a, a e r}$ were given $20 \%$ of the values used in the fermentation mode in ADM 1 to account for the higher efficiency of aerobic compared to anaerobic uptake. As a simplification, it is assumed that each VFA is similarly distributed and taken up in similar quantities by each of the three acidogenic biomass groups. Then, an overall biomass yield is defined for the aerobic uptake of the each VFA and this value is set to be equal to five times the fermentative biomass yield of the respective VFA (based on the values used in ADM 1). Finally, a $1 / 3$ of this overall biomass yield is allocated for each of the acidogenic biomass groups. $I_{1}$ and $I_{2}$ denote the standard inhibition functions used in ADM 1 (Batstone et al., 2002).

The stoichiometric matrix for the ADM 1-Ox model, after inclusion of the VFA oxidation processes, is shown in Table 1 (soluble components only). The stoichiometric matrix for the particulate components (not shown here) is now included with six different yield coefficient factors for each of the three acidogenic biomass groups. These are; fermentative yield due to the uptake of sugar or amino acids or long chain fatty acids (LCFA), aerobic yield due to the uptake of sugar or amino acids or LCFA, and four additional yield coefficients (each of these is equal to a $1 / 3$ of the overall aerobic yield of the respective VFA) from the uptake of valerate, butyrate, propionate and acetate.

All the kinetic and stoichiometric parameters are mainly adopted from the general values suggested in the standard ADM 1 model. No parameter estimation is attempted.

\subsection{Experimental}

\subsubsection{Batch experiments}

Two batch experiment series, BT 1 (Batch Test 1) and $B T 2$, fed with starch with the initial concentration of $1.09 \mathrm{kgCOD} / \mathrm{m}^{3}$, (COD - chemical oxygen demand) were conducted at $35{ }^{\circ} \mathrm{C}$ incubation temperature for more than 15 days periods until the gas generation stopped. These miniature batch reactors of $100 \mathrm{ml}$ total volume and $50 \mathrm{ml}$ liquid phase volume were operated under different initial air headspace volumes $(0-32 \mathrm{ml})$ and the volumetric gas generation was measured on a daily basis. Each of the different aeration conditions was tested with multiple reactors in parallel. Gas composition and the liquid phase compound analyses were carried out at the end of the experimentation period.

$B T 1$ and $B T 2$ series were alike in operation except for the two different inoculums used. BT 1 was inoculated with a culture obtained from a large scale anaerobic digester treating chemically precipitated primary sludge from municipal wastewater in Porsgrunn municipality (Norway). The inoculum for BT 2 was taken from the semi continuous feed laboratory anaerobic digester described below, during its early operation. This difference in inoculum lead to different initial particulate matter and biomass contents in BT 1 and BT 2, although the initial feed condition was similar.

\subsubsection{Semi continuous feed digester}

A bench top scale laboratory bioreactor of $5.5 \mathrm{~L}$ total volume and $3.3 \mathrm{~L}$ liquid volume was operated for 170 days at $35^{\circ} \mathrm{C}$ temperature under the organic loading rate of $0.33 \mathrm{kgCOD} /\left(\mathrm{m}^{3} \cdot d\right)$ and a hydraulic retention time (HRT) of 33 days. The digester was provided with different aeration conditions during its operation (Fig. 1 and 2). The aeration was carried out by direct injection of air into the liquid phase of the reactor immediately after the daily feeding of the reactor.

A detailed description of the experimental and analytical procedures adopted in these laboratory experiments can be found elsewhere (Botheju et al., 2010a,b). 


\begin{tabular}{|c|c|c|c|c|c|c|c|c|c|c|c|c|c|c|c|c|c|c|c|c|c|}
\hline 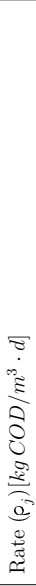 & & 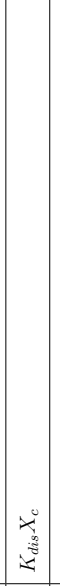 & 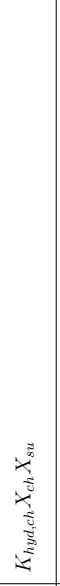 & 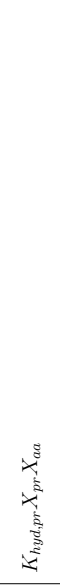 & 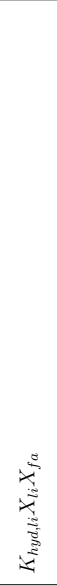 & 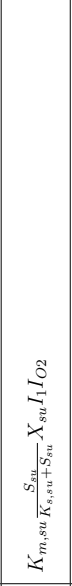 & 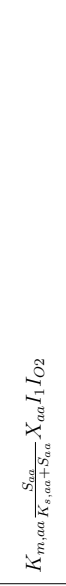 & 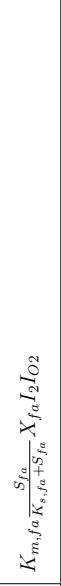 & 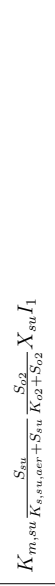 & 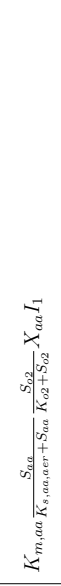 & 焉 & $\frac{1}{c}$ & 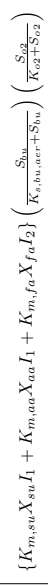 & 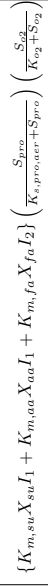 & 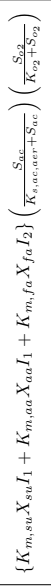 & 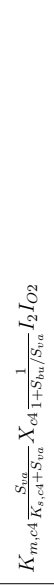 & 离 & 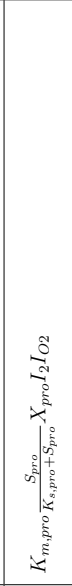 & 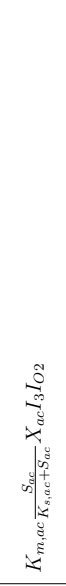 & 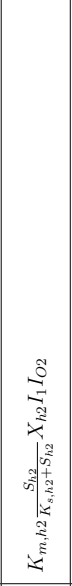 & 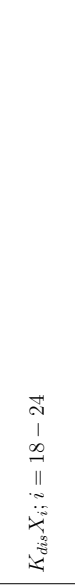 \\
\hline$\stackrel{?}{\stackrel{\sim}{\sim}}$ & 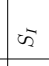 & $\mathrm{E}^{\frac{8}{0}}$ & & & & & & & & & & & & & & & & & & & \\
\hline$\stackrel{\approx}{\approx}$ & $\overbrace{}^{2}$ & & & & & & & & 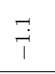 & $\stackrel{\text { ঙุ }}{\uparrow}$ & 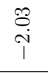 & $\underset{i}{\stackrel{\leftrightarrow}{i}}$ & $\stackrel{\infty}{\stackrel{\infty}{\dagger}}$ & $\underset{\overrightarrow{1}}{\vec{T}}$ & 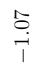 & & & & & & \\
\hline$\vec{\sigma}$ & $w^{3}$ & & & & & 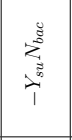 & 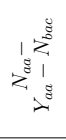 & 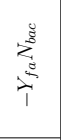 & 总 & 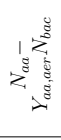 & i & 总 & 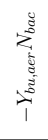 & 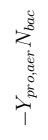 & i & 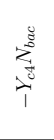 & 造 & 总 & 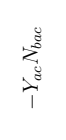 & 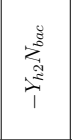 & \\
\hline$\stackrel{ }{\approx}$ & $\omega^{0}$ & & & & & 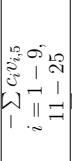 & 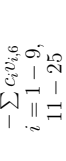 & & 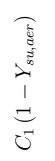 & 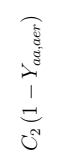 & 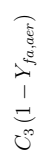 & 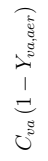 & 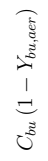 & 然 & 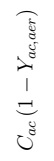 & & & 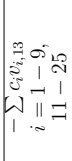 & $\begin{array}{ll}0 & 0 \\
1 & \text { a } \\
1 & 1 \\
1 \| & 1\end{array}$ & 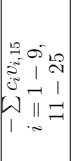 & \\
\hline$\approx$ & 売 & & & & & & & & & & & & & & & & & & -1.2 & 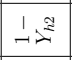 & \\
\hline$\stackrel{\infty}{\sim}$ & $v^{2}$ & & & & & 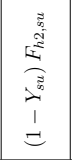 & 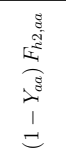 & $\begin{array}{l}\stackrel{\infty}{0} \\
\stackrel{0}{0} \\
\stackrel{1}{1} \\
=\end{array}$ & & & & & & & & $\begin{array}{l}\frac{28}{0} \\
0 \\
0 \\
18 \\
1 \\
=\end{array}$ & 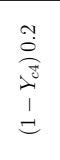 & 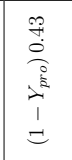 & & $\vec{\imath}$ & \\
\hline 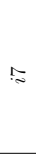 & $v^{g}$ & & & & & 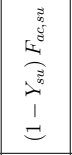 & 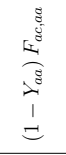 & $\begin{array}{l}\stackrel{5}{0} \\
\stackrel{0}{0} \\
\dot{1} \\
= \\
=\end{array}$ & & & & & & & $\uparrow$ & 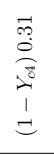 & $\begin{array}{l}\stackrel{\infty}{\circ} \\
\stackrel{0}{\overrightarrow{0}} \\
\stackrel{1}{1} \\
=\end{array}$ & 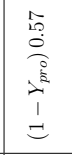 & $\uparrow$ & & \\
\hline$:$ & $v^{\frac{2}{2}}$ & & & & & 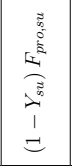 & 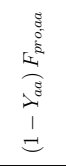 & & & & & & & $\vec{\imath}$ & & 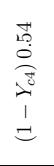 & & $\vec{\imath}$ & & & \\
\hline 2 & v.ّ. & & & & & 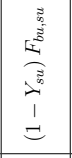 & 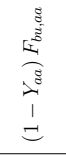 & & & & & & $\vec{\imath}$ & & & & \urcorner & & & & \\
\hline$\stackrel{*}{*}$ & $v^{\frac{5}{2}}$ & & & & & & 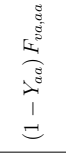 & & & & & $\vec{\imath}$ & & & & $\vec{\imath}$ & & & & & \\
\hline$\cong$ & $\omega^{ \pm}$ & & & & ${ }^{2}$ & & & $\imath$ & & & 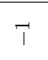 & & & & & & & & & & \\
\hline$\approx$ & $v_{2}^{g}$ & & & - & & & $\vec{\imath}$ & & & $\vec{\imath}$ & & & & & & & & & & & \\
\hline$\approx$ & $\omega_{0}^{5}$ & & $r$ & & 10 & $\vec{\imath}$ & & & $\vec{\imath}$ & & & & & & & & & & & & \\
\hline & 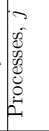 & $\therefore$ & 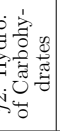 & 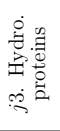 & 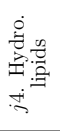 & 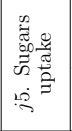 & & 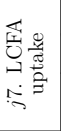 & & & & & & & & 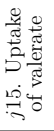 & 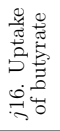 & 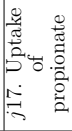 & 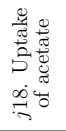 & 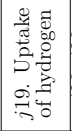 & 5. \\
\hline
\end{tabular}

Table 1: Stoichiometric matrix of the ADM 1-Ox model for the soluble components. 


\subsection{Simulations}

The simulations are carried out using the VFA oxidation included ADM 1-Ox model implemented in the Aquasim 2.1 simulation tool. For simulating the oxygenation in a batch reactor configuration, a diffusion link is defined for describing the transfer of oxygen as well as methane, $\mathrm{CO}_{2}$, and $\mathrm{N}_{2}$ between the air headspace and the liquid volume of the reactors which are introduced as complete mixed reactor compartments. In the case of the continuous mode digester, the oxygen injection is simulated as a direct input stream to the liquid phase.

\section{Results}

\subsection{Semi Continuous feed digester}

Figure 1 shows the simulated and experimentally observed $\mathrm{CH}_{4}, \mathrm{CO}_{2}$ and total biogas generation of the (semi) continuous feed reactor for the $170 d$ operation period. The simulated gas generation correctly predicts the observed initial transient production variations of the experimental digester. The reactor did not reach a true steady state due to the variation of oxygen load during the operation and the slow changes in the microbial population due to generation times of several weeks. The simulated $\mathrm{CO}_{2}$ generation accurately follows the experimentally observed $\mathrm{CO}_{2}$ generation dynamics. The simulated methane and total biogas generation moderately predicted the experimental data at the high oxygen load region $\left(10.1 \% \mathrm{O}_{2}\right.$ during $80 d$ to $108 d$ ). The model simulates the main observed trends quite well, such as: Methane and total biogas generation is reduced with increasing aeration (0 to $10.1 \%$ ) and this effect is reversed with reducing aeration. This shows that the negative effect of free oxygen is reversible, implying that the oxygen did no permanent damage to the anaerobic culture. The $\mathrm{CO}_{2}$ generation increased with increasing $\mathrm{O}_{2}$ load and reduced with decreasing $\mathrm{O}_{2}$ load.

The effects of oxygenation on biogas generation and quality can further be observed from the $\mathrm{CH}_{4} / \mathrm{CO}_{2}$ ratio curves for the experimental and simulated data (Fig. 2). The model predicts the experimentally observed variations quite closely. The largest deviations are for the highest oxygen load of $10.1 \% \mathrm{O}_{2}$. The model predicts somewhat better biogas quality than observed, implying that some additional or stronger negative effect of oxygen than simulated occurs. Figure 2 further confirms that the biogas generation dynamics of this bioreactor shows almost no hysteresis upon increasing and decreasing oxygenation levels within the range tested.
The simulated total and soluble organic matter (measured as COD), shown in Fig. 3a, are also in agreement with the experimental data, except for a short initial period during which the actual reactor conditions could have been quite different from the conditions simulated. The COD responses to oxygenation are hardly visible in this tested oxygenation range. Both the simulated and experimental $p H$ are near neutral throughout the operation (Fig. 3b).

High accumulation of VFA at the early operation period followed by a significantly reduced VFA content in later operation was observed in the experiment. A similar trend is predicted by the model simulation but the transition to low and stable VFA conditions took much longer in the experiment (Figs. 3c, 3d). The simulation only marginally illustrates the slight variations of VFA under the subsequent step changes in aeration levels.

\subsection{Batch Experiments}

Under batch operating conditions, both the experiments and the simulations suggested a positive response on methane generation to increasing $\mathrm{O}_{2}$ load in the range of $0-16 \%$. Figure 4 illustrates the experimental and model predicted ultimate methane generation for the batch experiments 1 and 2 (BT 1 \& $B T$ 2) conditions. The close resemblance between experimental data points and the simulated points confirms the applicability of this model for predicting the oxygen effects on methane generation under batch feed conditions. Based on the validity of these results, the model was further used to simulate higher oxygen loads (Fig. 5) in order to understand the effects of oxygen at high aeration conditions in batch feed mode. Under the operating conditions of BT 1, the simulations suggest that a maximum methane yield can be obtained at $14 \%$ oxygen load (Fig. 5); however, the positive effect of oxygenation, relative to the zero oxygen condition, continues until $72 \%$ oxygen load. When increasing the oxygen load beyond this point, the oxygen effect becomes solely negative. The methane generation, nevertheless, continues beyond $100 \%$ oxygenation. This is due to the fact that the $\mathrm{O}_{2}$ percentage load is calculated here based only on the starch feed, not considering the particulate matter present in the inoculum. Hydrolysis of these particulate matters contributes to additional methane potential. The increase of the methane yield with increasing oxygenation up to the peak point can be approximated by a linear variation (coefficient of determination, $R^{2}=0.91$ ) with a gradient of $11.9 \mathrm{ml} / \mathrm{g} C O D$ per percent $\mathrm{O}_{2}$. The reducing methane yield beyond the peak point is also linear $\left(R^{2}=0.997\right)$ with a slope of $-2.6 \mathrm{ml} / \mathrm{g} C O D$ per percent $\mathrm{O}_{2}$. This linear reduction stage is then followed by a region which can best be described by a power 


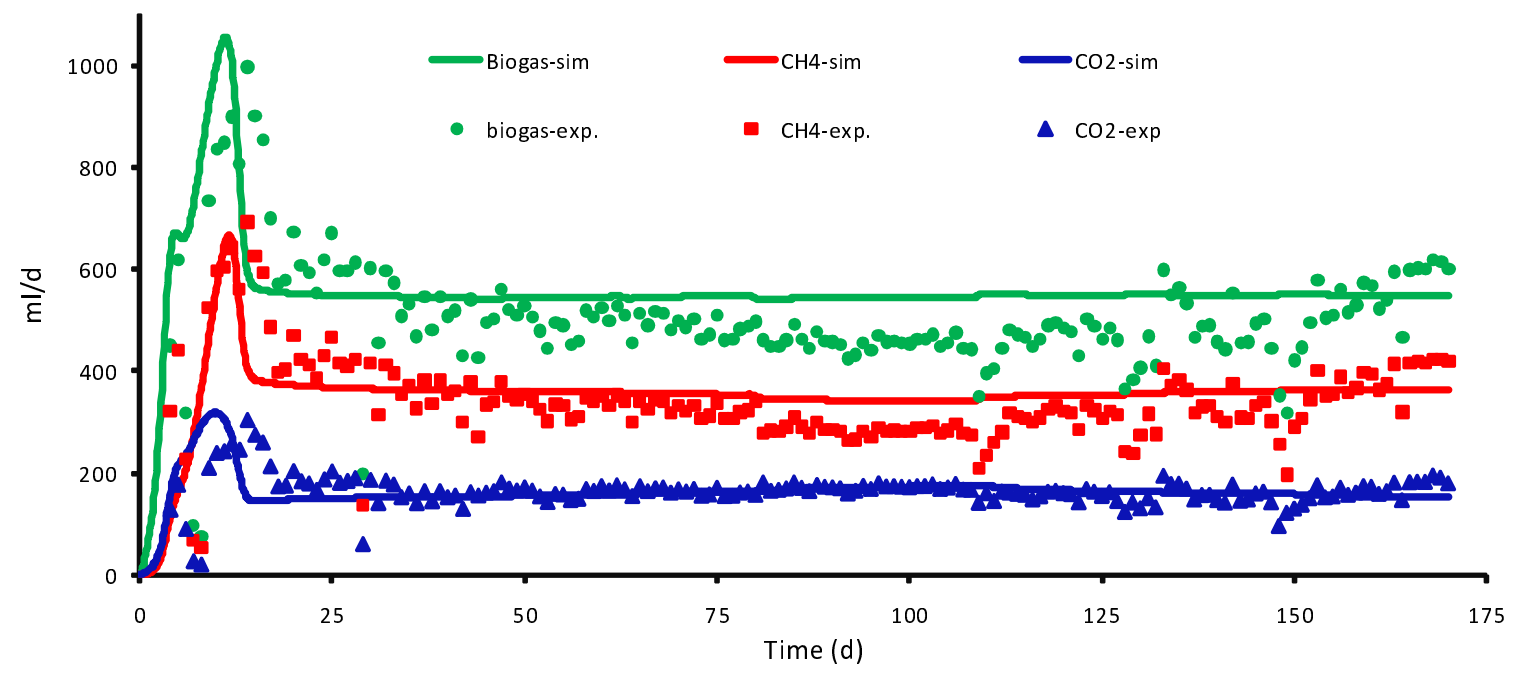

Figure 1: Experimental and simulated time variations of $\mathrm{CO}_{2}, \mathrm{CH}_{4}$ and total biogas of the (semi) continuous digester.

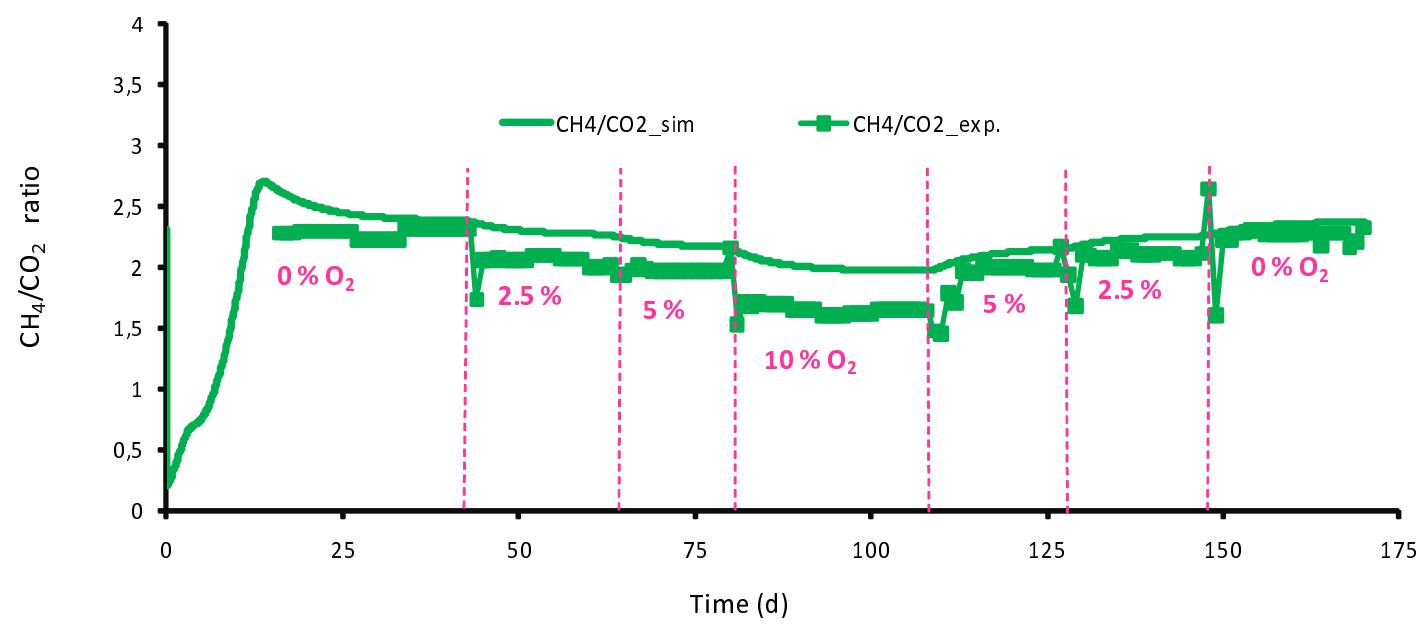

Figure 2: Experimental and simulated time variation of $\mathrm{CH}_{4} / \mathrm{CO}_{2}$ ratio under varying oxygen levels of the (semi) continuous digester. 


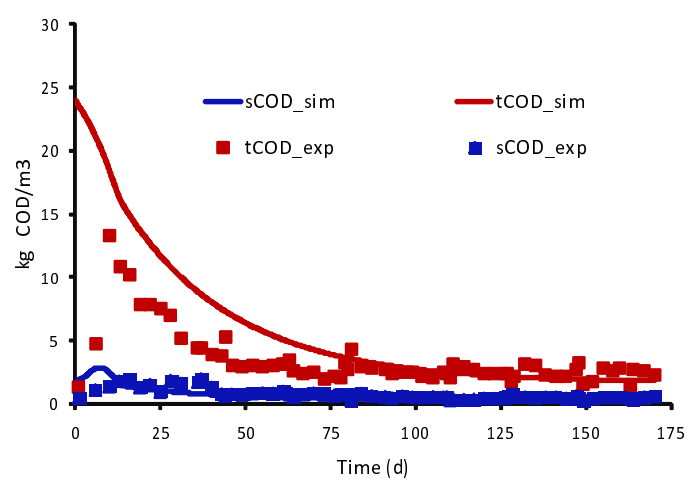

(a) Reactor COD variation.

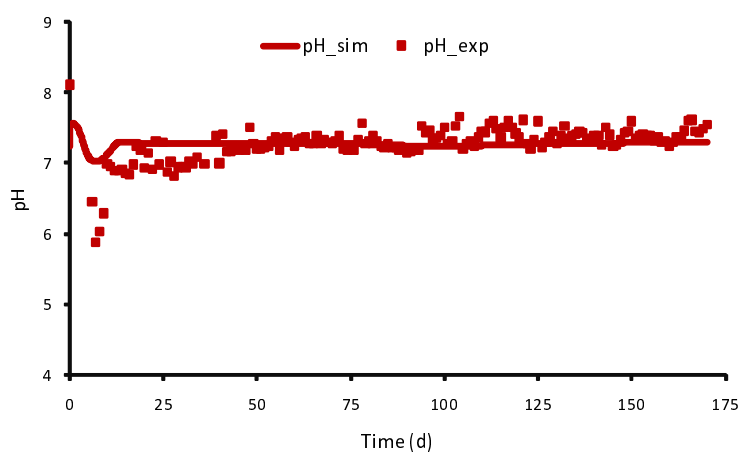

(b) Reactor $p H$.

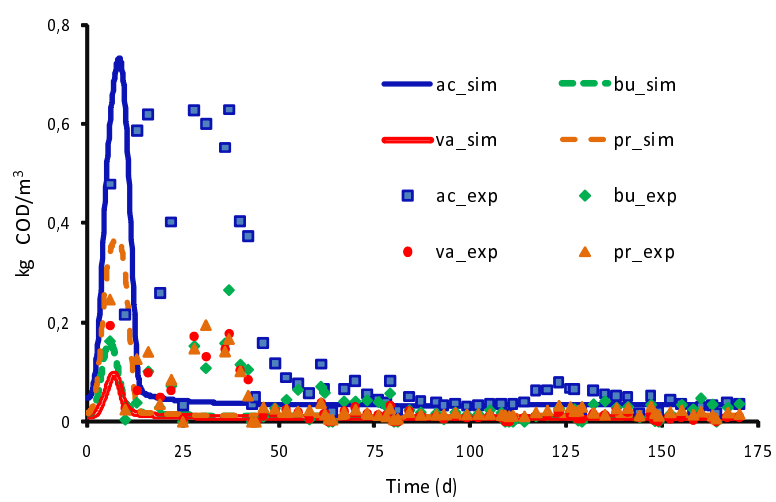

(c) Volatile fatty acids (VFA).

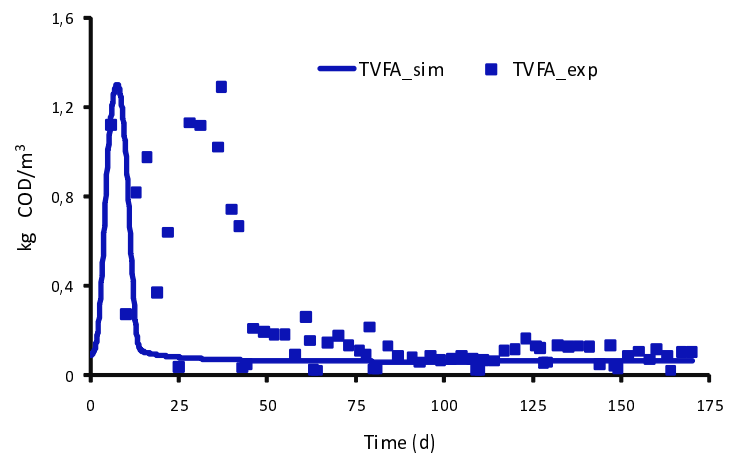

(d) Total VFA.

Figure 3: (a-d): Experimentally observed and simulated parameter variations for the semi continuous feed anaerobic digester.

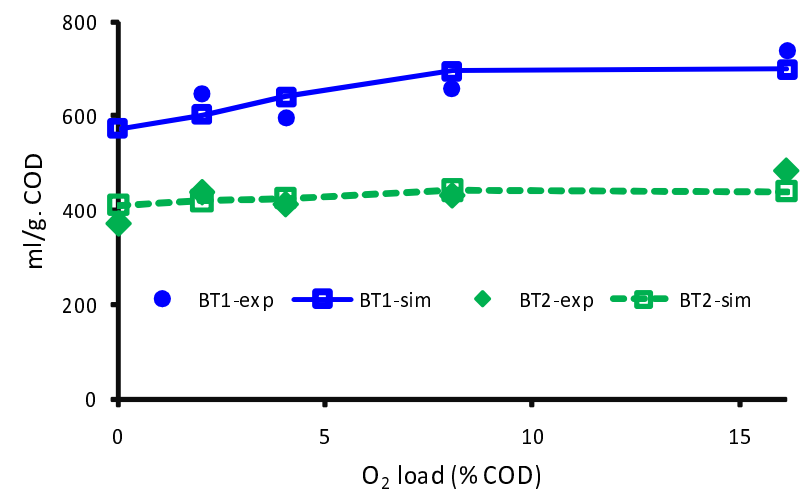

Figure 4: Experimental and simulated $\mathrm{CH}_{4}$ yields for the test series $B T 1$ and $B T 2$.

law type $\left(R^{2}=0.95\right)$ behavior (Fig. 5).

The simulations are then further utilized to study the oxygen effects under different initial biomass concentrations $\left(X_{B}\right)$, different hydrolysis rate coefficients $\left(K_{h}\right)$ and different gas-liquid mass transfer coefficients $\left(k_{L} a\right)$. The COD distributions at these various operating conditions are established based on the simulation data. Figure $6(\mathrm{a}-\mathrm{h})$ depict some of the key results obtained in this analysis.

A prominent feature noticed here is that the optimum oxygenation point (OOP) corresponding to the maximum methane yield, shifts to the left (Figs. 6 and 7) when increasing the initial biomass concentration $\left(X_{B}\right)$. For the initial biomass concentrations of $5,10,20$ and $40 \mathrm{mg} / \mathrm{L}$ (at a fixed hydrolysis rate constant of $10 \mathrm{~m}^{3} /(\mathrm{kgCOD} . d)$. (overall second order) and keeping all other conditions similar), the observed optimum oxygen levels are $14,10,8$ and $0.5 \%$, respectively (Fig. 6b, 6d, 6e and 6h). At high biomass concentrations, simulations found a negative impact of oxygenation (data not shown). The negative impact of oxygen at low oxygenation levels, was, however minor.

Increasing the hydrolysis rate coefficients $\left(K_{h}\right.$ - overall second order) leads to shifting of the optimum oxygenation point, OOP, once again, to the left (Figs. 6 and 8). At the initial biomass concentration of $5 \mathrm{mg} / \mathrm{L}$ (and keeping all the other conditions similar), use of $K_{h}$ values of 1,10 and $100 \mathrm{~m}^{3} /(\mathrm{kgCOD} . d)$ results in OOPs of 32,14 and $4 \%$, respectively (Figs. 6a, 6b and 6c). At the initial biomass concentration of $40 \mathrm{mg} / \mathrm{L}$, $K_{h}$ values of $0.5,1$ and $10 \mathrm{~m}^{3} /(\mathrm{kgCOD} . d)$ give optimum oxygen loads of 48,32 and $0.5 \%$, respectively (Figs. 6f, 6g and 6h).

The effect of the gas-liquid mass transfer coefficient $\left(k_{L} a\right)$ on the optimum oxygenation point was investigated. It is revealed that the effect is minor. Yet, decreasing the $k_{L} a$ value slightly shifts the optimum oxygen load to the right. At the conditions 


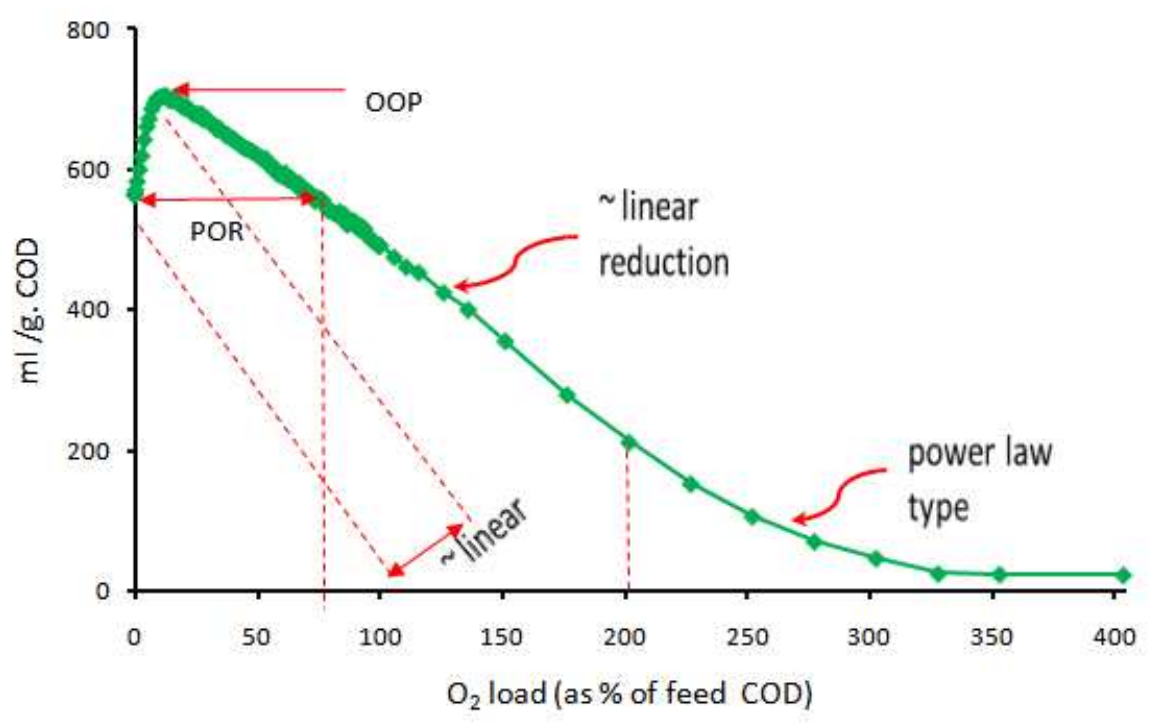

Figure 5: Simulated $\mathrm{CH}_{4}$ yield variation with oxygenation level, for the $B T 1$ conditions (OOP = optimum oxygenation point ; POR = positive oxygenation range).

of $5 \mathrm{mg} / \mathrm{L}$ initial biomass concentration and the $K_{h}$ of $10 \mathrm{~m}^{3} /(\mathrm{kgCOD} . \mathrm{d}), k_{L} a$ values of $4000,400,40$ and $4 d^{-1}$ results in OOPs of $14,14,16$ and $17 \%$, respectively.

The general trend observed in all the COD distribution analyses is that the increasing oxygen loads result in decreasing soluble COD and increasing particulate COD. The minimum particulate COD is observed near the optimum oxygenation point for methane production. The optimum oxygenation, hence, offers a combination of maximum energy yield and better effluent water quality (with low organic particle content).

\section{Discussion}

The close correlations between the experimental data gathered for continuous and batch mode bioreactors and the simulation predictions of the ADM 1-Ox model confirm the appropriateness of using the proposed model for analyzing oxygen effects in anaerobic digestion.

ADM 1-Ox simulations carried out under batch feed conditions reveal the existence of an optimum oxygenation point (OOP) corresponding to maximum methane yield in a given digestion system. Within the range of zero oxygen to this optimum oxygenation point, the oxygen effect is increasingly positive with respect to the methane yield. After passing the OOP, increasing oxygenation causes a decreasing effect on the methane generation. Yet the relative positive response due to oxygen introduction may continue further until it reaches a higher oxygenation point where the methane yield becomes equal to its strict anaerobic operation value. After this iso-methane yield point, the oxygen effect becomes sheer negative. For the sake of reference, we shall define this oxygen load range which is offering a positive impact on methane yield relative to the strictly anaerobic scenario as the "positive oxygenation range" (POR - Figs. 5 and 7).

Increasing initial biomass concentration $\left(X_{B}\right)$ and increasing hydrolysis rate coefficient $\left(K_{h}\right)$ decrease the OOP and also shrink the POR (Figs. 7 and 8). If the $X_{B}$ or/and $K_{h}$ are sufficiently high, both the OOP and POR can approach zero, extinguishing any positive response on methane generation due to oxygenation. Since the hydrolysis rate depends on both the biomass content and the hydrolysis rate coefficient, the observed behavior of OOP and POR indicates that the lower the "hydrolysability" of the system, the more pronounced is the positive response of oxygen in AD. Partial aeration is therefore especially interesting with respect to the degradation of slowly degradable substrates: The positive oxygen effects can more clearly be observed for slowly biodegrading (low $\left.K_{h}<20 \mathrm{~m}^{3} /(\mathrm{kgCOD} . \mathrm{d})\right)$ compounds than easily degradable (high $K_{h}$ ) matter (Fig. 9). According to Fig. 9, the variation of OOP with $K_{h}$ under the conditions tested here is best described by a power law type relationship. The variation of OOP with $X_{B}$ can basically be described as linear (Fig. 10). Figs. 7-10, further indicate that $K_{h}$ has a higher impact on the OOP and the POR than the biomass concentration, implying that the nature of the degrading substrate 


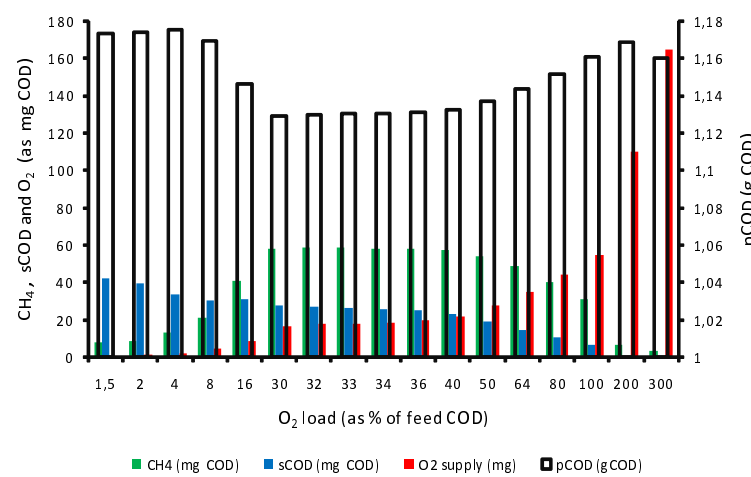

(a) $X_{B}=5 \mathrm{mg} / \mathrm{L}, K_{h}=1$.

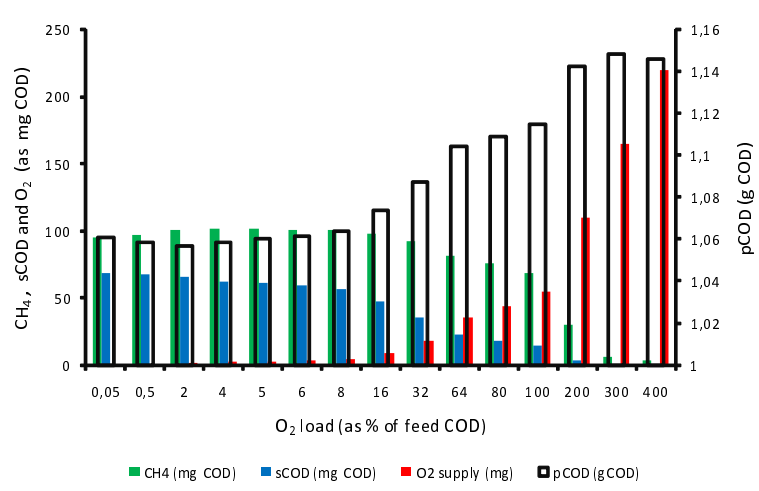

(c) $X_{B}=5 \mathrm{mg} / \mathrm{L}, K_{h}=100$.

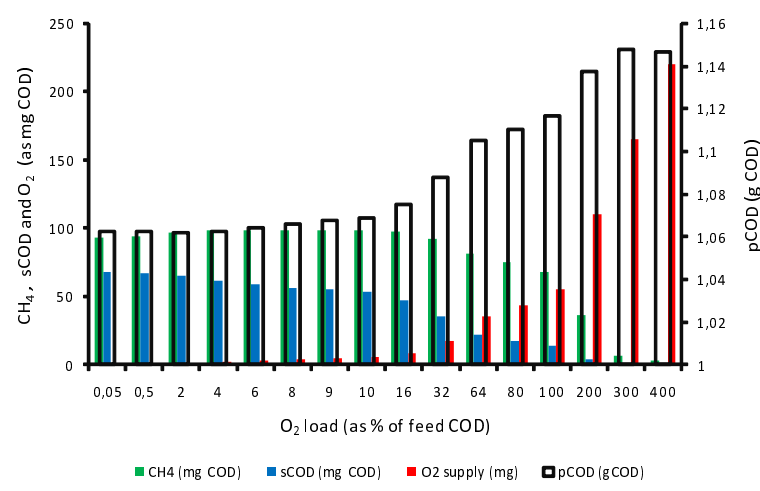

(e) $X_{B}=20 \mathrm{mg} / \mathrm{L}, K_{h}=10$.

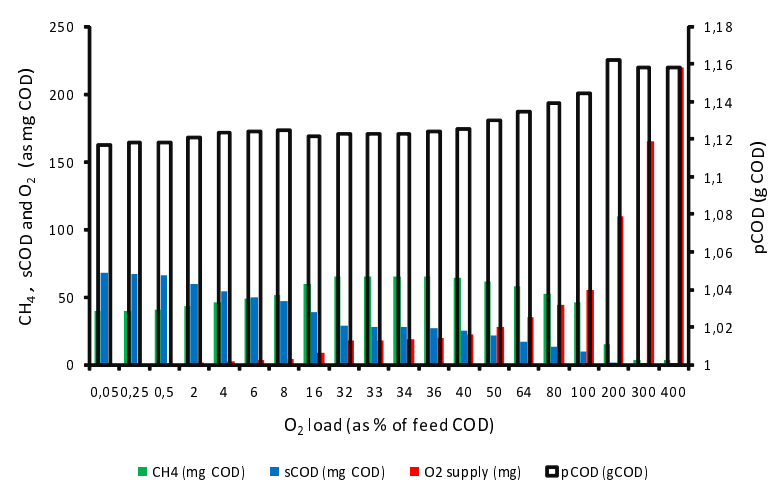

(g) $X_{B}=40 \mathrm{mg} / \mathrm{L}, K_{h}=1$.

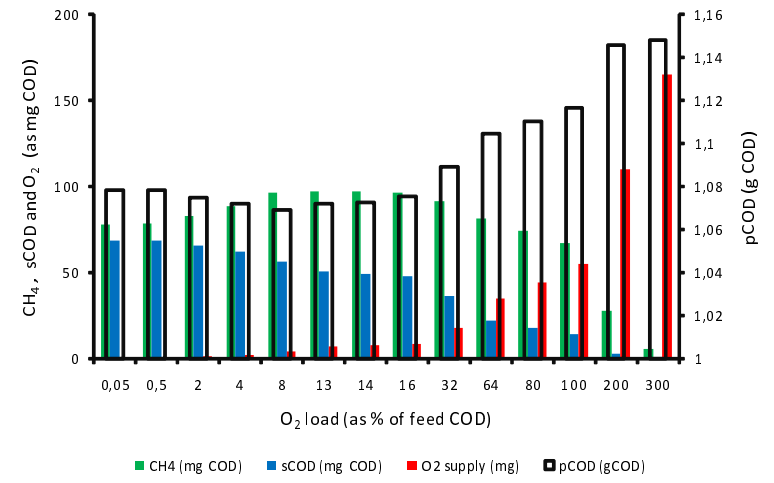

(b) $X_{B}=5 \mathrm{mg} / \mathrm{L}, K_{h}=10$.

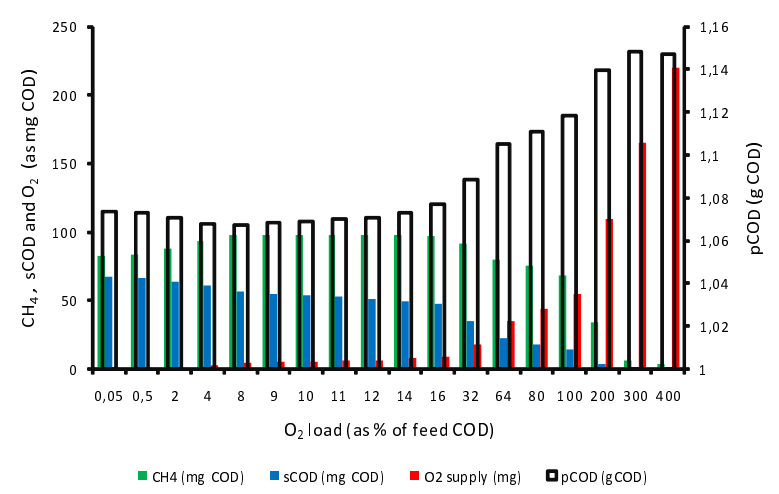

(d) $X_{B}=10 \mathrm{mg} / \mathrm{L}, K_{h}=10$.

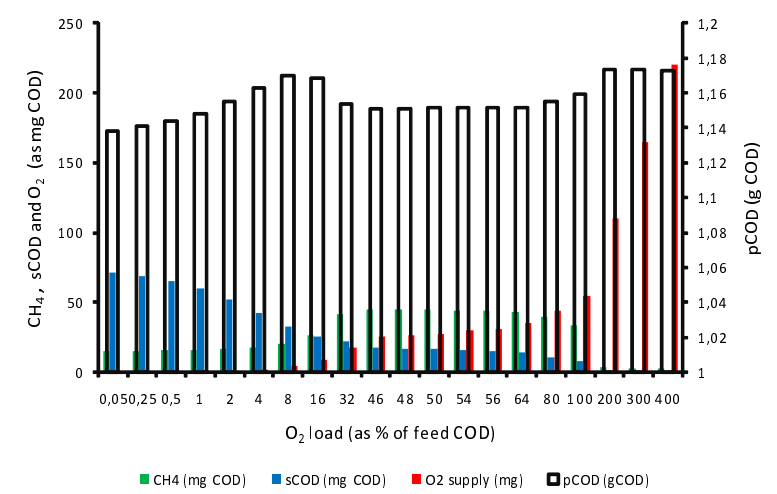

(f) $X_{B}=40 \mathrm{mg} / L, K_{h}=0.5$.

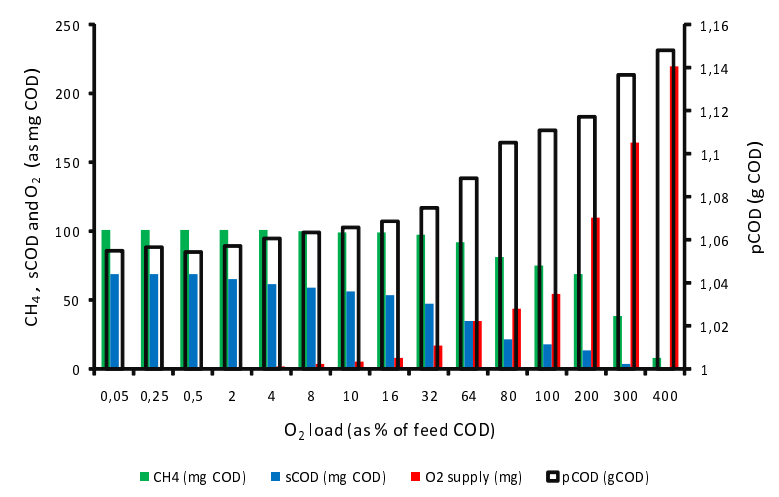

(h) $X_{B}=40 \mathrm{mg} / \mathrm{L}, K_{h}=10$.

Figure 6: (a-h): COD distributions at various oxygenation levels with different operating conditions of $X_{B}$ and $K_{h}\left(\right.$ fixed $\left.k_{L} a=4000 d^{-1}\right)$. 


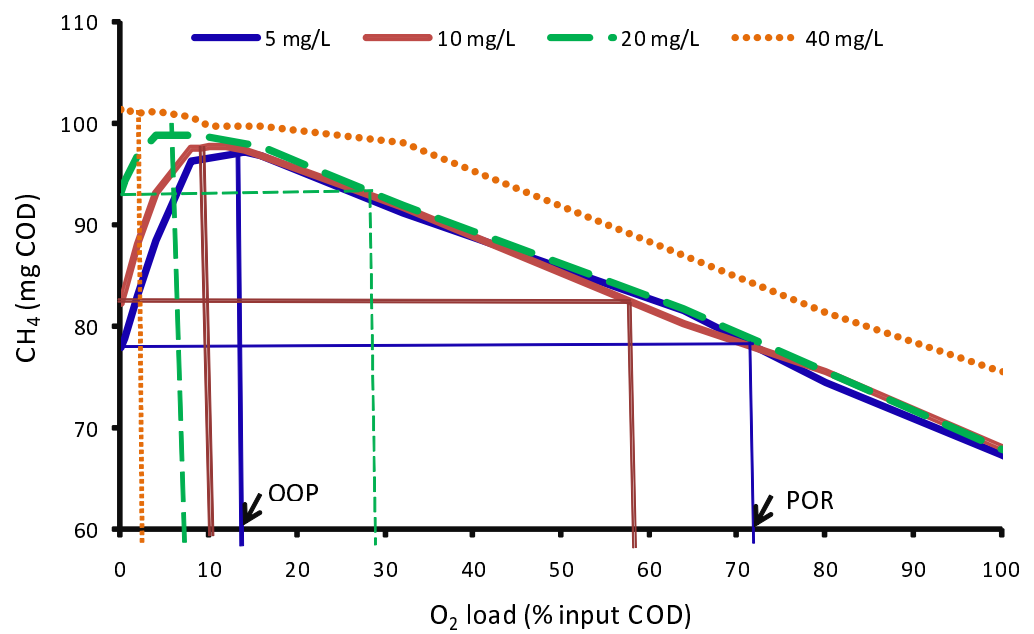

Figure 7: ADM 1-Ox batch mode simulations for different initial biomass concentrations $\left(X_{B}\right)$ indicating the shifting of OOP and POR $\left(K_{h}=10 \mathrm{~m}^{3} / \mathrm{kgCOD.d} ; k_{L} a=4000 \mathrm{~d}^{-1}\right.$, starch feed of $\left.1.09 \mathrm{kgCOD} / \mathrm{m}^{3}\right)$.

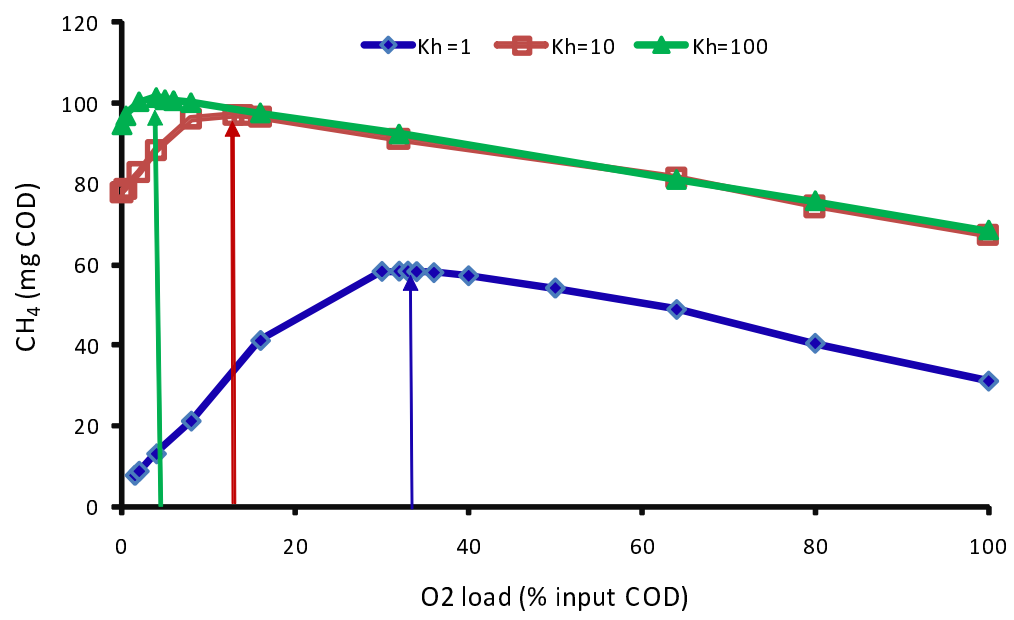

Figure 8: ADM 1-Ox batch mode simulations for different hydrolysis rate coefficients $\left(K_{h}\right)$ indicating the OOP shift $\left(X_{B}=5 \mathrm{mg} / \mathrm{L}, k_{L} a=4000 \mathrm{~d}^{-1}\right.$, starch feed of $\left.1.09 \mathrm{kgCOD} / \mathrm{m}^{3}\right)$. 


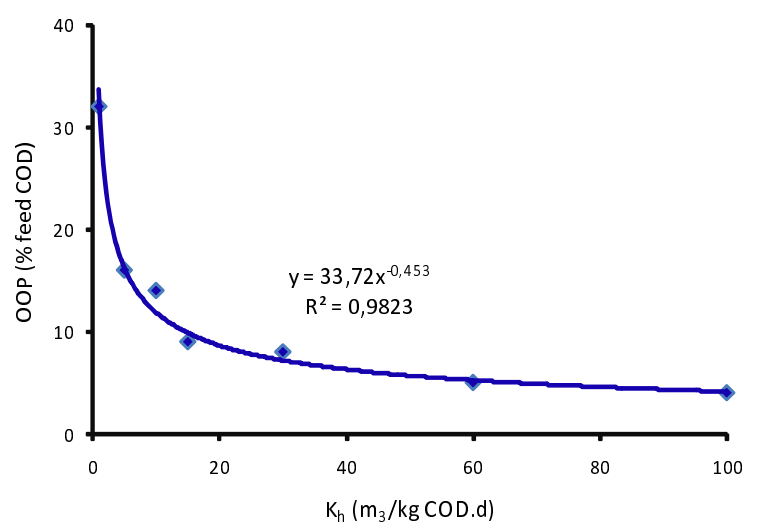

Figure 9: OOP variation with $K_{h}$.

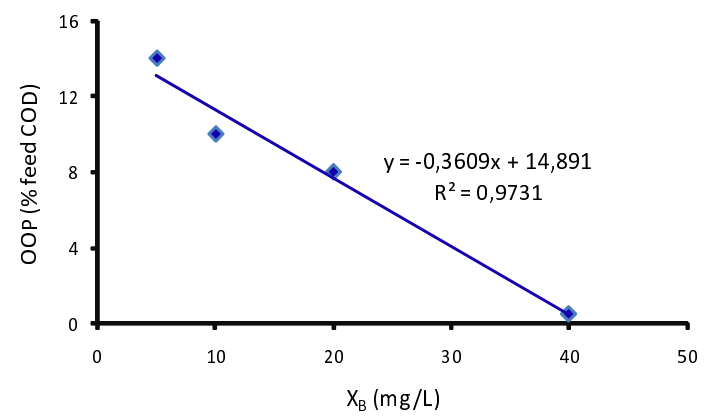

Figure 10: OOP variation with $X_{B}$.

holds a key role on deciding positive or negative oxygen effects.

Increasing oxygenation results in decreased soluble COD (sCOD) and increased particulate COD (pCOD) (Fig. 6). Aerobic respiration can account for this trend as readily degradable sCOD is used for aerobic respiration and biomass (represented in pCOD) production. Minimum pCOD content is observed at the OOP (Fig. $6)$. This situation is regarded as an optimal condition where the substrate is mainly converted into methane and only smaller amounts into biomass by aerobic respiration.

The batch experiments suggest that the oxygen effects in continuous mode digesters can depend on several additional factors to those tested. The reactor biomass concentration, for example, depends on the organic loading rate (OLR), the hydraulic retention time (HRT) and sludge age. The oxygen effects may depend on these operational factors. Under the conditions tested in the semi continuous experiment described here, only negative effects are observed due to oxygenation. This is also confirmed by the ADM 1-Ox simulations of the same case. Further analysis using experimentation and simulation of ADM 1-Ox may facilitate a better understanding of the effects of these additional continuous mode reactor parameters on oxygen impacts.

\section{Conclusions}

The predictions from the oxygen included anaerobic digestion model, ADM 1-Ox, are generally in agreement with the experimental observations made in batch and semi continuous feed anaerobic digesters operating under various oxygenation conditions.

Methane yield of anaerobic digesters can either be positively or negatively influenced by oxygenation, based on a number of factors including the reactor biomass concentration and the hydrolysis rate coefficient. Negative effects of oxygen dominated in the continuous feed mode investigated, while positive net effects were observed in some batch conditions.

The simulations and experimental observations alike suggest the existence of an optimum oxygenation level (OOP), corresponding to a maximum methane and low biomass yield, that depends on several operating parameters. OOP depends mainly on how hard it is to degrade (hydrolyze) the feed, with no positive net effect of oxygenation for easily degradable substrates.

\section{Acknowledgement}

This study is funded by grants from the Norwegian Research Council. Thanks to the staff members of Telemark University College for their support, especially the Chief Laboratory Engineer, Hildegunn H. Haugen, for her quality control in laboratory related matters.

\section{Nomenclature}

$a a$
$a c / a c t / a c e t$
$b u / b u t y$
$c h$
$d$
$D O$
$f a / F a / l c f a$
$k_{h y d}$
$k_{m}$
$k_{s}$
$k_{L} a$
$L C F A$
$l i$
$p r / p r o$
$p r o p$
$r$
$S$
su/ms

amino acids

acetic, acetate

butyric, butyrate

carbohydrates

days (time unit)

dissolved oxygen

fatty acids /LCFA

first order hydrolysis rate constant

uptake rate constant

half saturation constant (Monod)

oxygen transfer coefficient $\left(d^{-1}\right)$

long chain fatty acids

lipids

protein

propionate, propionic

reaction rate

conc. of a soluble component

sugar/monosaccharides 


$\begin{array}{ll}v a / v a l & \text { valeric, valerate } \\ V F A & \text { volatile fatty acids } \\ x, X & \text { conc. of a particulate component } \\ X_{a a} & \text { amino acids degraders (biomass conc.) } \\ X_{a c} & \text { acetoclastic methanogens } \\ X_{c 4} & \text { butyrate and valerate degraders } \\ X_{f a} & \text { LCFA degraders } \\ X_{h 2} & \text { hydrogenotrophic methanogens } \\ X_{\text {prop }} & \text { propionate degraders } \\ X_{s u} & \text { sugar (monosaccharide) degraders }\end{array}$

\section{References}

Batstone, D. J., Keller, J., Angelidaki, I., Kalyuzhnyi, S., Pavlostathis, S. G., Rozzi, A., Sanders, W., Siegrist, H., and Vavilin, V. Anaerobic digestion Model No.1. IWA publishing, 2002.

Botheju, D., Lie, B., and Bakke, R. Oxygen effects in anaerobic digestion. Modeling, Identification and Control, 2009. 30(4):191-201. doi:10.4173/mic.2009.4.1.

Botheju, D., Samarakoon, G., Chen, C., and Bakke, R. An experimental study on the effects of oxygen in bio-gasification; part 1. In Proceedings of the International Conference on Renewable Energies and Power Quality (ICREPQ 10), Granada (Spain), 2325 March. 2010a.

Botheju, D., Samarakoon, G., Chen, C., and Bakke, R. An experimental study on the effects of oxygen in bio-gasification; part 2. In Proceedings of the International Conference on Renewable Energies and Power Quality (ICREPQ 10), Granada (Spain), 2325 March. 2010b.

Johansen, J. E. and Bakke, R. Enhancing hydrolysis with microaeration. Water science and Technology, 2006. 53(8):43 - 50. doi:10.2166/wst.2006.234.

Polanco, M. F., Diaz, I., Pérez, S. I., Lopes, A. C., and Polanco, F. F. Hydrogen sulphide removal in the anaerobic digestion of sludge by micro-aerobic processes: pilot plant experience. Water Science and Technology, 2009. 60(12):3045 - 3050. doi:10.2166/wst.2009.738. 